\title{
The Mid-Continent Geographic Science Center
}

\section{Mission}

The mission of the Mid-Continent Geographic Science Center (MCGSC) is to conduct geographic research for the prediction, assessment, and mitigation of natural and manmade hazards, to monitor land-use and land-cover change, and to relate land-cover dynamics to population, disease, and ecosystem change so policy makers at all levels of government can make informed decisions regarding current and future issues affecting their geographic regions.

\section{History}

The Mid-Continent Geographic Science Center is one of several new United States Geological Survey (USGS) geographic science centers where remotely sensed imagery, digital cartographic, and other geospatial data are used to address a variety of current natural-resource management, hazard response and mitigation, land-use change, and environmentalquality issues. MCGSC is collocated with the USGS Missouri Water Science Center, and the USGS National Geospatial Technical Operations Center. Our history of geographic research goes back to 1987 when the USGS Mid-Continent Mapping Center established a small research group to provide leadership and direction in geographic information science, and provide technical assistance and training on a variety of topics, including using geographic information and image processing systems to better understand environmental and socioeconomic issues.

Since 1987, the Center has developed a cadre of scientists and technical support staff with expertise in land cover change analysis, urban geography, spatial analysis, vegetation community mapping, fluvial geomorphology, sediment geochemistry, and surrogate water-quality monitoring. The goal of MCGSC is to expand current expertise to include the assessment and mitigation of hazards. This will be done through active partnerships with other Federal and state agencies, universities, and private non-governmental organizations.

\section{Expertise}

The Mid-Continent Geographic Science Center staff includes research scientists and a technical staff with general expertise in regional, physical, and urban geography; cartography; geology; and hydrology, and collective expertise in Geographic Information Science, including remote sensing, image processing, and geospatial data collection and analysis. MCGSC scientists have been active participants in regional, national, and international research on a variety of topics that have included regional land-use change, vegetation community mapping, environmental contamination, and physical process modeling. MCGSC scientists and staff also have provided introductory and applied training in the use of remote sensing, image processing, GIS, and GPS.

\section{Additional Information}

For more information about the Mid-Continent Geographic Science Center please write or call:

\section{Emitt Witt, Director}

USGS Mid-Continent Geographic Science Center

1400 Independence Road

Rolla, Missouri 65401

Phone: (573) 308-3679

Fax: (573) 308-3794

Email: ecwitt@usgs.gov

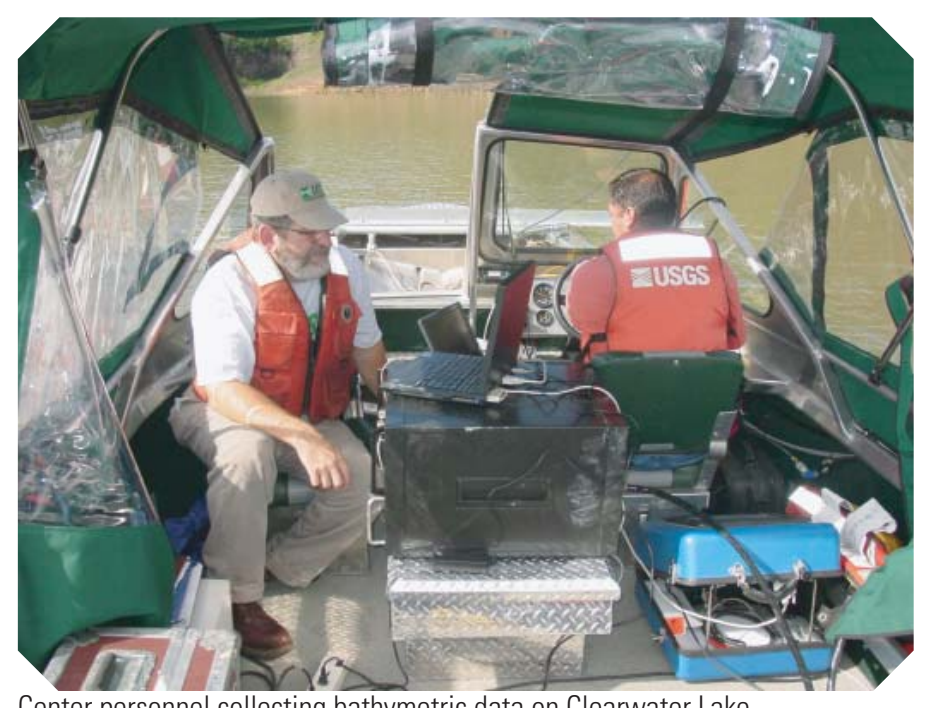

Center personnel collecting bathymetric data on Clearwater Lake.

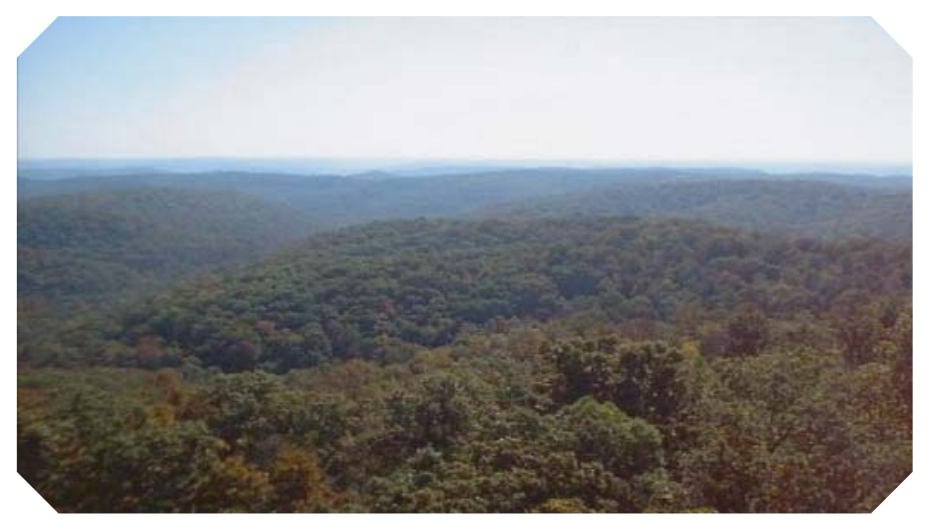

The Mid-Continent Geographic Science Center is located in the Ozarks of southern Missouri. 